\title{
Comparative testing of crack formation in strain-hardening cement-based composites (SHCC)
}

\author{
Gideon P. A. G. van Zijl • Volker Slowik • \\ Romildo D. Toledo Filho $\cdot$ Folker H. Wittmann • \\ Hirozo Mihashi
}

Received: 22 February 2014 / Accepted: 16 February 2015 / Published online: 10 June 2015

(C) RILEM 2015

\begin{abstract}
Two of the main activities of RILEM Technical Committee 208-HFC Subcommittee 2 were the preparation and publication of the state-of-the-art report on durability of strain hardening cement-based composites (SHCC), and the performance of comparative laboratory testing on SHCC. In this paper the comparative mechanical tests are reported, as performed in laboratories of five participating institutions. The purpose was to investigate and compare the crack patterns in terms of crack widths and spacing, and
\end{abstract}

G. P. A. G. van Zijl ( $\square)$

Department of Civil Engineering, Stellenbosch

University, 7602 Matieland, Private Bag

$\mathrm{X} 1$, Stellenbosch, South Africa

e-mail: gvanzijl@sun.ac.za

URL: http://www.civeng.sun.ac.za

V. Slowik

Leipzig University of Applied Sciences, Leipzig,

Germany

R. D. Toledo Filho

Universidade Federal do Rio de Janeiro, Rio De Janeiro, Brazil

F. H. Wittmann ( $\square)$

Aedificat Institute Freiburg, Freiburg, Germany

e-mail: wittmann@aedificat.de

F. H. Wittmann

Qingdao Technological University, Qingdao, China

H. Mihashi

Tohoku University, Sendai, Japan subsequently to make recommendations for a suitable test setup and procedure towards characterizing cracking in this class of materials. Such standardized procedures are required for future systematic and objective research towards durability of these materials in their in-service conditions, i.e. their resistance to deterioration processes in the cracked state. Standardized test procedures are also required for durability testing and guidelines for structural design with SHCC, which is the focus of follow-up committee activity in TC 240-FDS.

Keywords SHCC · Cracking · Durability ·

Tensile test

\section{Introduction}

In order to establish reliable durability test procedures for strain hardening cement-based composites (SHCC) in the cracked state, a consistent method of mechanical loading is imperative. The comparison of pre-cracking procedures for subsequent or simultaneous durability tests on SHCC specimens is the main objective of the work reported in this paper. Cracks in cement-based composites serve as access for ingress of materials associated with deterioration processes. Whilst the controlled crack width in SHCC is believed to be beneficial, leading to pseudo-strain hardening, associated ductility and toughness, the implications of multiple cracks for deterioration processes must be understood, 
modelled and verified. This paper reports on a comparative test series on SHCC by five laboratories participating in the RILEM Technical Committee 208-HFC, Subcommittee 2: Durability (TC208-SC2). The test series was performed to compare the SHCC tensile test results from laboratories with established SHCC test facilities, in order to identify the test procedure, specimen size and shape, crack observation method and crack distribution characterization procedure that produce the most consistent crack results.

TC208-SC2 recently published a state-of-the-art report (STAR) on the durability of SHCC [9-11]. This report serves as a summary of durability related test results on SHCC in its relatively short existence since the 1990s, but also indicates research needs. In parallel to the STAR, the TC208-SC2 also embarked on comparative testing of SHCC, in order to establish a suitable test setup and procedure towards characterizing cracking in this class of materials. Such standardized procedures are required for future systematic and objective research towards durability of these materials in their in-service conditions, i.e. their resistance to deterioration processes in the cracked state. Standardized test procedures are also required for durability testing and guidelines for structural design with SHCC, which is the focus of follow-up committee activity in TC 240-FDS.

Several researchers have reported multiple crack formation under direct tensile load and crack width and/or spacing measurements in SHCC (e.g. [1, 8, 11]), in textile reinforced concrete (e.g. [6]) and ultra-high strength fibre reinforced composites [16]. The importance of cracks for ingress of water and deleterious substances has been illustrated by various of these authors and by [17]. Different specimen shapes and sizes as well as boundary conditions have been used by the respective authors. This paper compares results on crack width measurements performed by five laboratories in a comparative test series, in order to identify the most suitable specimen size and test setup, towards standardisation of crack formation and durability test procedures. Assessment criteria for the test procedures were their practicability, an appropriate repeatability of the results, the reusability of the cracked specimens for durability tests and, most importantly, the generation of crack patterns that resemble those being formed in field applications of SHCC.
The following laboratories participated in the comparative test series on SHCC:

(L1) Leipzig University of Applied Sciences, Germany, Prof V Slowik, C Wagner and $\mathrm{N}$ Bretschneider

(L2) Qingdao Technological University, Prof FH Wittmann and Penggang Wang

(L3) Rio de Janeiro, Brazil, Researcher Prof RD Toledo Filho, assisted by MS Magalhães

(L4) Stellenbosch University, Department of Civil Engineering, South Africa, Researcher Prof GPAG van Zijl, assisted by $\mathrm{H}$ Smit and $\mathrm{C}$ Adendorff

(L5) Tohoku University, Japan, Researcher Prof H Mihashi, assisted by T Kikuta

\section{Comparative series}

The agreed procedure was to use a base SHCC mix with $2 \%$ by volume polyvinyl alcohol (PVA) short fibre, prepare the specimens as per each laboratory's specification and experience, perform uniaxial tension tests on the specimens in setups developed by the respective laboratories, and use best practice to measure the crack widths at various average tensile strain levels. Suggested strain levels were 0.2, 0.5, $1 \%$, and subsequent $0.5 \%$ intervals up to ultimate tensile strain.

The test results were to be reported in a standardized format, stating the participating laboratory, mixture proportions, specimen geometry, test setup description, stress-strain graphs, crack width measurement equipment, software and procedure, average crack width, maximum crack width and average crack spacing per tensile strain level, and finally crack width histograms per strain level. Note that only surface crack measurements were reported.

Finally, two types of SHCC were tested. Whilst all five laboratories tested fine-grained SHCC, containing sand aggregate with maximum particle size less than $0.3 \mathrm{~mm}$, Laboratories 1, 3 and 5 also prepared and tested coarse sand SHCC. The purpose was to develop SHCC from naturally available sand, whilst still achieving crack control and strain hardening up to at least $1 \%$ in tensile strain. 


\section{Mix ingredients and procedures}

Standard mix proportions were agreed upon based on past experiences of the respective participants and locally available materials, allowing minor adjustments to ensure that multiple cracking could be achieved. Note that no ingredient materials were distributed amongst the laboratories, but each made use of that which is available in their respective laboratories and industries. PVA fibres, type REC15 with length $\left(L_{\mathrm{f}}\right) 12 \mathrm{~mm}$ and diameter $\left(d_{\mathrm{f}}\right) 0.04 \mathrm{~mm}$ were obtained from Kuraray, Japan. Laboratory L1 (Leipzig) used the same fibre type, but with fibre length $8 \mathrm{~mm}$.

The mixes are summarised in Table 1 for both fine sand and coarse sand SHCC. Most laboratories kept the initially indicated mix proportions, with the exception of a lower amount of water by Laboratory 1 . Cement type also varied, as indicated. The conditions for curing, fresh properties and selected hardened properties are summarised in Table 2. Clearly different procedures were followed, and the test ages range from 14 to 28 days. Details of the respective curing conditions and characterising test methods are described in detail in [7] for L3, [2] for L4 and in [3] for L5.

\section{Tensile test setup and procedures}

In Table 3, the uniaxial tensile test specimen geometries and the test conditions are summarised. Figure 1 shows the specimen geometries and setups in greater detail. It is clear that a significant range of specimen gauge area cross-section size $(30 \mathrm{~mm} \times 13 \mathrm{~mm}$ up to $60 \mathrm{~mm} \times 30 \mathrm{~mm}$ ) was used, and lengths ranging from $80 \mathrm{~mm}$ to $120 \mathrm{~mm}$. For more detail on the test setup, the reader is referred to [14, 13] for L1, [15] for L2, [7] for L3, [2] for L4 and [3] for L5.

Non-rotational boundaries are believed to introduce to a large extent uniform strain distributions in crosssections of a specimen in a tensile test. The influence of such non-rotational and rotational boundaries on the results of tensile tests specifically on SHCC was studied by [4, 5], who point out that rotational boundaries allow increased deformation and crack formation on the side of the specimen where the first crack appears, which may lead to lower first crack strength, ultimate strength and ultimate strain deducted from tests with rotational boundaries. To study the influence of end conditions on SHCC, alternate boundary conditions were applied by the participating laboratories according to their existing tensile test facilities at the time.

\section{Crack measurement}

In Fig. 2, the crack observation equipment is shown for each group, in addition to typical cracked specimens. Multiple cracks could be observed in the specimens by all laboratories. They were not all parallel, however, nor always fully developed over the specimen width.

Table 1 SHCC mixture proportions

\begin{tabular}{|c|c|c|c|c|c|c|c|c|}
\hline \multirow{2}{*}{$\begin{array}{l}\text { Participant } \\
\text { laboratory }\end{array}$} & \multicolumn{2}{|l|}{ Cement } & \multirow{2}{*}{$\begin{array}{l}\text { Fly ash } \\
\left(\mathrm{kg} / \mathrm{m}^{3}\right)\end{array}$} & \multirow{2}{*}{$\begin{array}{l}\text { Water } \\
\left(\mathrm{kg} / \mathrm{m}^{3}\right)\end{array}$} & \multicolumn{2}{|l|}{ Sand } & \multicolumn{2}{|c|}{ PVA fibre } \\
\hline & $\begin{array}{l}\text { Amount } \\
\left(\mathrm{kg} / \mathrm{m}^{3}\right)\end{array}$ & Type & & & $\left(\mathrm{kg} / \mathrm{m}^{3}\right)$ & $\begin{array}{l}\text { Max particle } \\
\text { size }(\mathrm{mm})\end{array}$ & $\begin{array}{l}\text { Amount } \\
\left(\mathrm{kg} / \mathrm{m}^{3}\right)\end{array}$ & $\begin{array}{l}\text { Length } \\
(\mathrm{mm})\end{array}$ \\
\hline \multicolumn{9}{|l|}{ Fine sand (FS) } \\
\hline L1. Leipzig & 550 & CEM I 42.5 & 650 & 373 & 550 & 0.25 & 26 & 8 \\
\hline L2. Qingdao & 550 & CEM I 42.5 & 650 & 395 & 550 & 0.30 & 26 & 12 \\
\hline L3. Rio de Janeiro & 550 & CEM II F-32 & 650 & 395 & 550 & 0.20 & 26 & 12 \\
\hline L4. Stellenbosch & 550 & CEM I 42.5 & 650 & 395 & 550 & 0.30 & 26 & 12 \\
\hline L5. Tohoku & 550 & CEM I 52.5 & 650 & 395 & 550 & 0.20 & 26 & 12 \\
\hline \multicolumn{9}{|l|}{ Coarse sand (CS) } \\
\hline L1. Leipzig & 560 & CEM I 42.5 & 690 & 417.6 & 460 & 1.00 & 26 & 8 \\
\hline L3. Rio de Janeiro & 560 & CEM II F-32 & 690 & 440 & 460 & 1.18 & 26 & 12 \\
\hline L5. Tohoku & 560 & CEM I 52.5 & 690 & 440 & 460 & 1.20 & 26 & 12 \\
\hline
\end{tabular}


Table 2 Specimen preparation

\begin{tabular}{|c|c|c|c|c|c|c|}
\hline Participant laboratory & Curing & $\begin{array}{l}\text { Test age } \\
\text { (days) }\end{array}$ & Flow (mm) & Air content $(\%)$ & $\begin{array}{l}f_{\mathrm{cu}} \\
(\mathrm{MPa})\end{array}$ & $\begin{array}{l}E \\
(\mathrm{GPa})\end{array}$ \\
\hline \multicolumn{7}{|l|}{ L1. Leipzig } \\
\hline $\begin{array}{l}\text { Fine sand series FS1 and } \\
\text { coarse sand series CS1 }\end{array}$ & $\begin{array}{l}2 \text { days in plastic mould under } \\
\text { wet burlap, stripped; } \\
23 \text { days in water at } 23{ }^{\circ} \mathrm{C} \text {; } \\
3 \text { days in wet burlap and } \\
\text { plastic foil at } 20^{\circ} \mathrm{C}\end{array}$ & 28 & - & - & - & - \\
\hline Fine sand series FS2 & $\begin{array}{l}2 \text { days in plastic mould under } \\
\text { wet burlap, stripped; } \\
5 \text { days in water at } 23{ }^{\circ} \mathrm{C} \text {; } \\
7 \text { days at } 20{ }^{\circ} \mathrm{C} \text { and } 95 \% \mathrm{RH}\end{array}$ & 14 & $\begin{array}{l}153 \text { (Hägermann } \\
\text { method) }\end{array}$ & $\begin{array}{l}9.0 \text { (Entrained-air } \\
\text { vessel method) }\end{array}$ & - & - \\
\hline L2. Qingdao & $\begin{array}{l}1 \text { day in steel mould under } \\
\text { wet burlap, stripped; } \\
20 \text { days at } 20{ }^{\circ} \mathrm{C} \text { and } \\
\mathrm{RH} \geq 95 \%\end{array}$ & 21 & - & - & - & - \\
\hline \multicolumn{7}{|l|}{ L3. Rio de Janeiro } \\
\hline Fine sand & $\begin{array}{l}1 \text { day in steel mould under } \\
\text { damp cloth, stripped; }\end{array}$ & 28 & 300 & 5.9 & 32.2 & 20.1 \\
\hline Coarse sand & $\begin{array}{l}27 \text { days in chamber at } 22{ }^{\circ} \mathrm{C} \\
\text { and } \mathrm{RH} \approx 100 \%\end{array}$ & 28 & 300 & 6.9 & 25.3 & 15.1 \\
\hline L4. Stellenbosch & $\begin{array}{l}1 \text { day in steel mould covered } \\
\text { with steel plate; } \\
13 \text { days in water at } 23{ }^{\circ} \mathrm{C}\end{array}$ & 14 & - & - & - & - \\
\hline \multicolumn{7}{|l|}{ L5. Tohoku } \\
\hline Fine sand & $\begin{array}{l}2 \text { days in steel mould at } \\
\mathrm{RH} \geq 95 \% \text {, stripped; }\end{array}$ & 28 & 220 (JIS R 5201) & $\begin{array}{l}10.5 \text { (C13-S mortar } \\
\text { air meter) }\end{array}$ & 28.0 & 19.0 \\
\hline Coarse sand & 26 days in water at $20^{\circ} \mathrm{C}$ & 28 & - & - & - & - \\
\hline
\end{tabular}

Compressive strength $f_{\text {cu }}$ and modulus of elasticity $E$ were tested on cylinders of diameter $50 \mathrm{~mm}$ and height $100 \mathrm{~mm}$

- Denotes that no measurements were taken

Different crack measurement methods were employed by the various laboratories. In L1, L3 and L5 digital image processing (DIP) was conducted by using high resolution cameras and standard commercial digital image processing software. In Leipzig (L1), the first series crack measurement (series FS1 and CS1) was done with low resolution, in the order of $50 \mu \mathrm{m}$. In series FS2 of this laboratory, an improved resolution of $10 \mu \mathrm{m}$ has been achieved. In Qingdao (L2) 2D photos were taken with a resolution of approximately $10 \mu \mathrm{m}$. In Stellenbosch (L4), 3D Aramis digital image correlation (DIC) was used with a $10 \mu \mathrm{m}$ resolution. Hence, in Laboratories L1 (series FS2), L2, L3, L4 and L5 approximately the same resolution of about $10 \mu \mathrm{m}$ was achieved. The various equipment and setups are illustrated in Fig. 2.
Contactless measurement of crack widths and patterns on SHCC specimens by photogrammetric analysis has been described in recent literature. High resolution digital images of cracked specimens are used in combination with software to measure crack widths in DIP [12]. In DIC, three-dimensional particle tracking and inter-particle deformation calculations are performed by analysis of sequential digital images. Through calibration, inter-particle deformations exceeding expected elastic deformation are defined as cracks, the widths of which are approximated as total minus elastic deformation [1].

Crack widths were determined at various positions along the specimen length, along a central vertical line by $\mathrm{L} 5$ and in the first series (FS1 and CS1) of L1, along three parallel vertical lines by L3 and L4, along four 
Table 3 Tensile specimens and setup

\begin{tabular}{|c|c|c|c|c|c|c|c|c|c|c|c|}
\hline \multirow[t]{2}{*}{$\begin{array}{l}\text { Participant } \\
\text { laboratory }\end{array}$} & \multicolumn{4}{|c|}{$\begin{array}{l}\text { Number of specimens } \\
\text { per series }\end{array}$} & \multicolumn{3}{|c|}{$\begin{array}{l}\text { Specimen gauge area } \\
\text { dimensions }(\mathrm{mm})\end{array}$} & \multirow[t]{2}{*}{$\begin{array}{l}\text { Test rate } \\
(\mathrm{mm} / \mathrm{min})\end{array}$} & \multicolumn{3}{|c|}{ Test fixture of ends } \\
\hline & 1 & 2 & 3 & 4 & $\mathrm{~L}^{\mathrm{a}}$ & $\mathrm{B}^{\mathrm{a}}$ & $\mathrm{T}^{\mathrm{a}}$ & & Type & $\begin{array}{l}\text { Bottom end } \\
\text { rotational fixture }\end{array}$ & $\begin{array}{l}\text { Top end } \\
\text { rotational fixture }\end{array}$ \\
\hline \multicolumn{12}{|l|}{ L1. Leipzig } \\
\hline Fine & 4 & 3 & & & 100 & 40 & 40 & $0.012-0.18$ & Glued & Fixed & Fixed \\
\hline Coarse & 4 & & & & & & & & & & \\
\hline L2. Qingdao & 5 & & & & 120 & 60 & 30 & $0.3^{\mathrm{b}}$ & Clamped & Free & Free \\
\hline \multicolumn{12}{|l|}{ L3. Rio } \\
\hline Fine & 5 & & & & 80 & 30 & 30 & 0.1 & Wedged & Fixed & Fixed \\
\hline Coarse & 5 & & & & & & & & & & \\
\hline L4. Stellenbosch & 4 & 3 & 3 & 4 & 80 & 30 & 16 & 4.8 & Clamped & Semi-fixed & Free \\
\hline \multicolumn{12}{|l|}{ L5. Tohoku } \\
\hline Fine & 6 & & & & 80 & 30 & 13 & 0.4 & Clamped & Fixed & Free \\
\hline Coarse & 6 & & & & & & & & & & \\
\hline
\end{tabular}

${ }^{a}$ The specimen gauge area length (L), breadth (B) and thickness (T) as illustrated in Fig. 1

b Approximate test rate, applied manually

parallel vertical lines by L2, and along five parallel vertical lines in the second series (FS2) by L1. Each crack that crossed either of the lines was captured and its width noted. From these cracks, the spacing, average and maximum width were determined, and the frequency distribution derived as will be presented in subsequent sections.

\section{Tensile test results}

In Fig. 3, typical stress-strain results of the tensile tests are shown. The results presented for Laboratory $\mathrm{L} 1$ are those from series FS1 and CS1, respectively. Note that crack widths were measured in the loaded state by all participating laboratories. Only laboratory L4 measured crack widths in the loaded state (series denoted by FS1 and FS2 in Fig. 3) as well as in the unloaded state (FS3 and FS4). So, the FS3 data set given in Table 4 for L4 represents the crack widths at zero stress and tensile strains 1 and $2 \%$, and the FS4 data set is for the unloaded state at tensile strain levels $0.2,0.5$ and $1 \%$. There is no significant difference in average crack widths in the loaded and unloaded state at the same tensile strain levels.

Figure 4 shows the average crack width evolution with average tensile strain as determined on the various specimens and gauge lengths in the participating laboratories. The results are summarized in Table 4, where also the coefficients of variation $(\mathrm{CoV})$ are included. The different crack measurement resolution $(50 \mu \mathrm{m})$ used in Laboratory L1 for series FS1 and CS1 appears to have led to significantly larger crack width observation data, as shown in Fig. 4a for Leipzig FS1. Clearly, Leipzig FS2, obtained with finer resolution $(10 \mu \mathrm{m})$ is in closer agreement with the other laboratories.

A further observation is that the $\mathrm{CoV}$ of the crack width is significantly smaller for the larger specimen sizes of L1 and L3, at $0.24-0.59$ versus up to 0.90 for the smaller fine sand specimen size of L4. Small size specimens of L5 containing fine sand are the exception. For coarse sand SHCC, the CoV for the larger specimens of L1 and L3 are also relatively low at $0.27-0.47$ when compared with up to 1.45 for the thin specimens of L5. The results from L2 generally show larger CoVs, up to 0.85 for the comparatively large specimens with fine sand. While various factors could contribute to the large $\mathrm{CoV}$, including fibre dispersion and test procedure, smaller sections may not be representative elementary volumes in terms of flaw distribution, leading to the larger scatter. Larger sections may be preferable, and also more suitable for specimen extraction for subsequent durability 


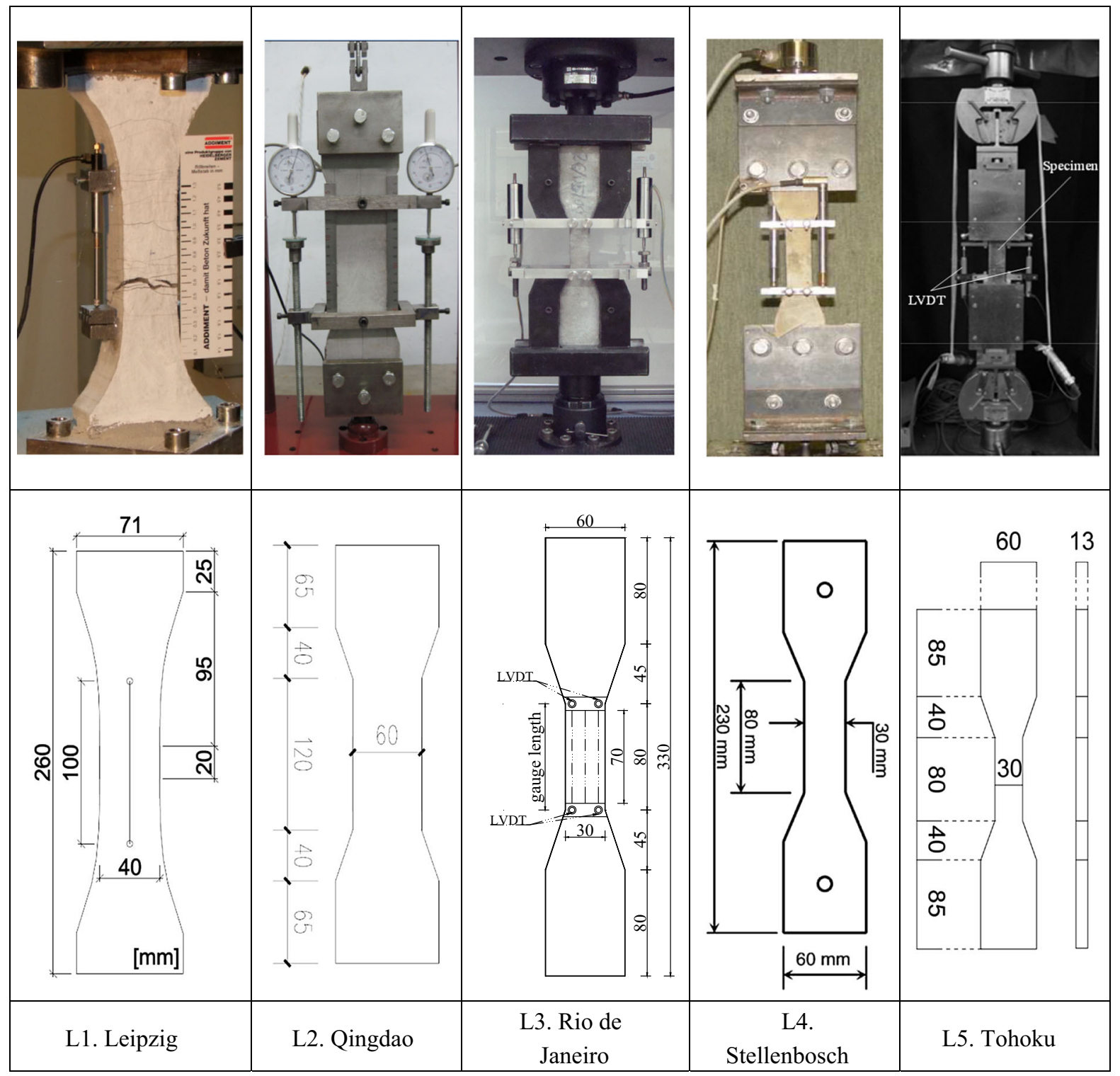

Fig. 1 Uniaxial tensile test specimens and setups in the participating laboratories

testing. For particularly thin sections or thin layer applications, thin specimens may be required but care should be taken to ensure that specimens are well processed and representative, also in terms of fibre orientation.

Note that all laboratories measured the cracks on the formed surface, i.e. the surface that faced the mould during casting. L2, Qingdao, measured the crack widths also on the finished surface, i.e. on the upper surface during casting. It appears that both average and maximum crack widths are different on these two surfaces. These differences require further investigation.

Average crack spacing is shown in Fig. 5 and summarized in Table 5. It appears that the average crack spacing reduces from roughly $7-40 \mathrm{~mm}$ at $0.5 \%$ strain, to a stable spacing of $2-7 \mathrm{~mm}$ at and beyond $3 \%$ strain. Crack saturation occurs at roughly $3 \%$ strain. This holds for both fine sand and coarse sand SHCC, although a lower ductility is apparent for coarse sand SHCC. The coarse sand specimens from Tohoku (L5), are the exception, maintaining an average 


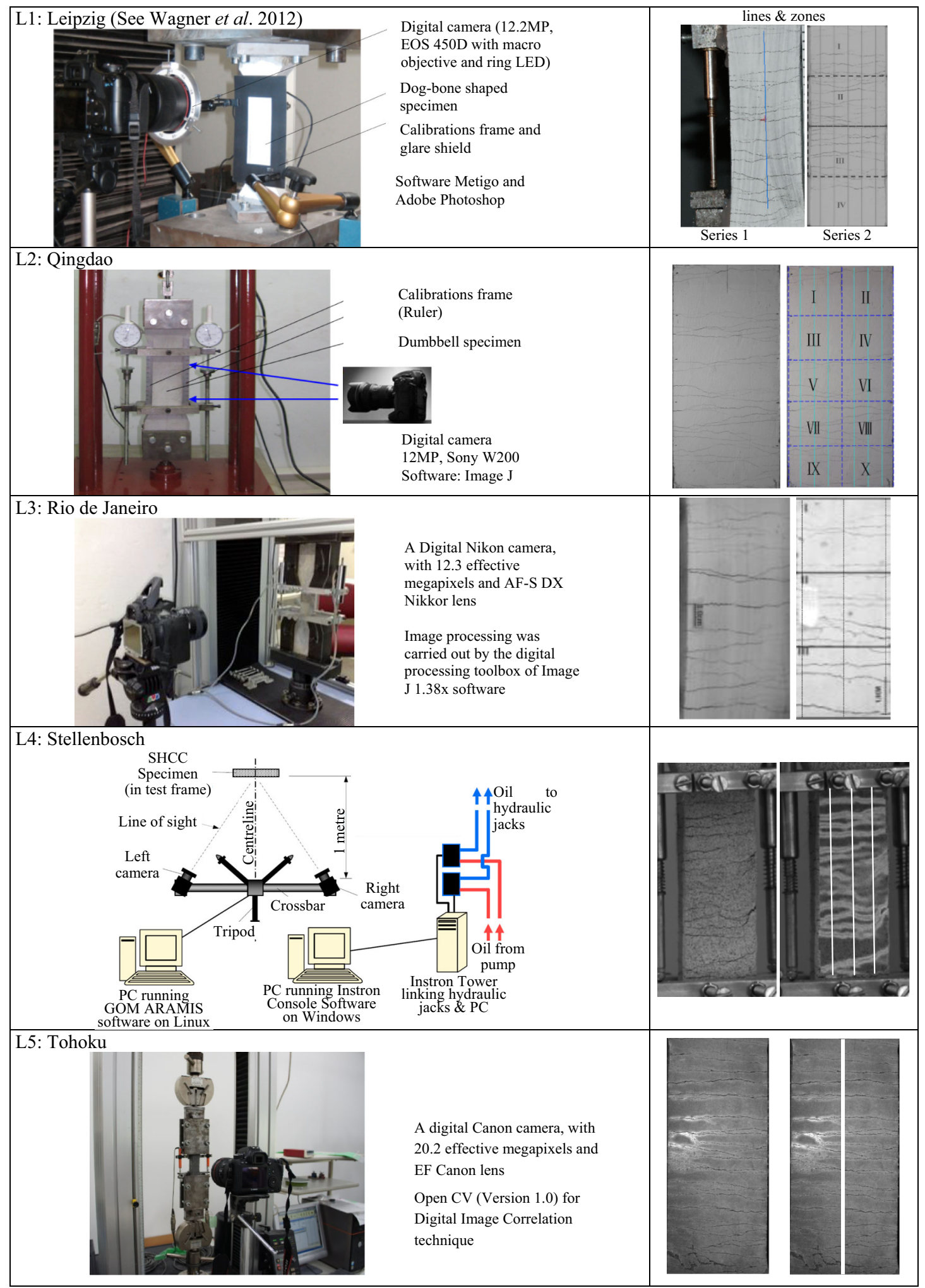

Fig. 2 Crack observation and measurement methods 


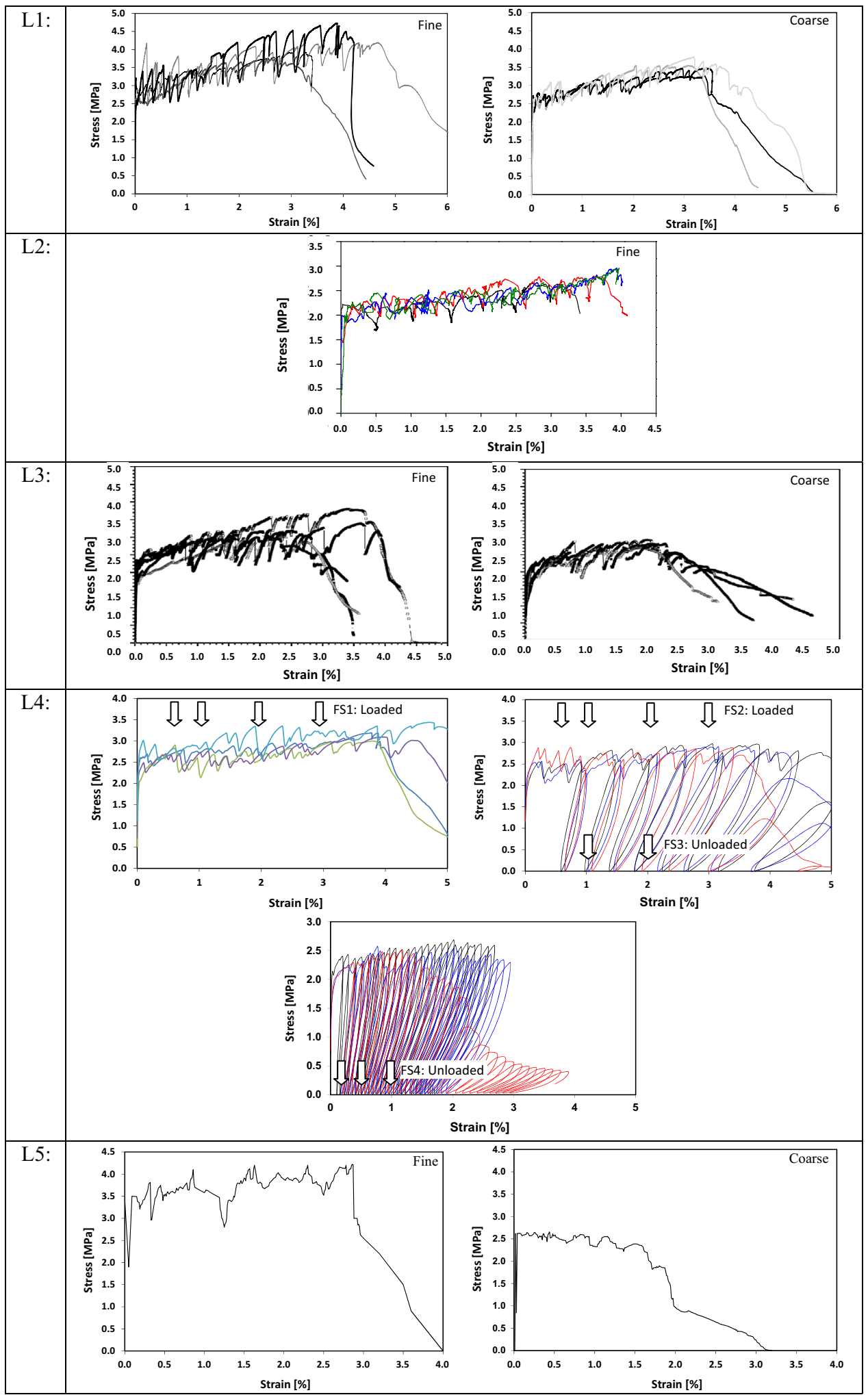

Fig. 3 Uniaxial tensile stress-strain results 
Table 4 Crack width data summary from all participating laboratories

\begin{tabular}{|c|c|c|c|c|c|c|c|c|c|}
\hline \multirow[t]{2}{*}{ Crack width $(\mu \mathrm{m})$} & \multicolumn{9}{|c|}{ Strain level $(\%)$} \\
\hline & 0.2 & 0.5 & 1 & 1.5 & 2 & 2.5 & 3 & 3.5 & 4 \\
\hline \multicolumn{10}{|l|}{ Fine sand SHCC } \\
\hline \multicolumn{10}{|l|}{ L1 } \\
\hline \multicolumn{10}{|l|}{ FS1 } \\
\hline Avg & - & 130 & 150 & - & 170 & - & 200 & - & - \\
\hline $\mathrm{CoV}$ & - & 0.31 & 0.40 & - & 0.53 & - & 0.55 & - & - \\
\hline Max & - & 170 & 240 & - & 370 & - & 530 & - & - \\
\hline \multicolumn{10}{|l|}{ FS2 } \\
\hline Avg & - & 47 & 53 & 60 & 65 & 74 & 77 & 80 & 93 \\
\hline $\mathrm{CoV}$ & - & 0.51 & 0.58 & 0.58 & 0.54 & 0.57 & 0.56 & 0.56 & 0.59 \\
\hline Max & - & 115 & 199 & 225 & 233 & 236 & 264 & 271 & 442 \\
\hline \multicolumn{10}{|l|}{$\mathrm{L} 2$} \\
\hline \multicolumn{10}{|l|}{ Formed surface } \\
\hline Avg & - & 69.9 & - & - & 62.7 & - & 74.3 & 82.5 & 87.8 \\
\hline $\mathrm{CoV}$ & - & 0.55 & - & - & 0.76 & - & 0.92 & 0.85 & 1.38 \\
\hline Max & - & 134.6 & - & - & 184.7 & - & 454.0 & 458.9 & 945.8 \\
\hline \multicolumn{10}{|l|}{ Finished surface } \\
\hline Avg & - & 37.2 & - & - & 32.2 & - & 41.0 & 38.7 & 38.1 \\
\hline $\mathrm{CoV}$ & - & 0.35 & - & - & 0.60 & - & 0.63 & 0.67 & 0.82 \\
\hline Max & - & 58.1 & - & - & 121.5 & - & 135.9 & 144.0 & 184.0 \\
\hline \multicolumn{10}{|l|}{ L3 } \\
\hline Avg & - & 54 & 66 & 67 & 65 & 65 & 69 & - & - \\
\hline $\mathrm{CoV}$ & - & 0.24 & 0.24 & 0.28 & 0.26 & 0.25 & 0.28 & - & - \\
\hline Max & - & 72 & 85 & 90 & 103 & 106 & 117 & - & - \\
\hline \multicolumn{10}{|l|}{ L4 } \\
\hline \multicolumn{10}{|l|}{ FS1 loaded } \\
\hline Avg & 33.9 & 46.0 & 50.3 & - & 54.6 & - & 57.6 & - & - \\
\hline $\mathrm{CoV}$ & 0.63 & 0.71 & 0.68 & - & 0.67 & - & 0.90 & - & - \\
\hline $\operatorname{Max}$ & 94 & 135 & 153 & & 195 & & 253 & & \\
\hline \multicolumn{10}{|l|}{ FS2 loaded } \\
\hline Avg & - & 42.1 & 41.6 & - & 50.0 & - & 61.0 & - & - \\
\hline $\mathrm{CoV}$ & - & 0.64 & 0.73 & - & 0.79 & - & 0.68 & - & - \\
\hline Max & & 105 & 158 & & 238 & & 245 & & \\
\hline \multicolumn{10}{|l|}{ FS3 unloaded } \\
\hline Avg & - & - & 42.3 & - & 48.4 & - & - & - & - \\
\hline $\mathrm{CoV}$ & - & - & 0.71 & - & 0.70 & - & - & - & - \\
\hline Max & - & - & 155 & - & 195 & - & - & - & - \\
\hline \multicolumn{10}{|l|}{ FS4 unloaded } \\
\hline Avg & 25.8 & 34.2 & 38.7 & - & - & - & - & - & - \\
\hline $\mathrm{CoV}$ & 0.50 & 0.83 & 0.72 & - & - & - & - & - & - \\
\hline Max & 55 & 118.3 & 138 & - & - & - & - & - & - \\
\hline \multicolumn{10}{|l|}{ L5 } \\
\hline Avg & - & 90 & 93 & - & 116 & - & 80 & - & - \\
\hline $\mathrm{CoV}$ & - & 0.11 & 0.55 & - & 0.50 & - & 0.25 & - & - \\
\hline
\end{tabular}


Table 4 continued

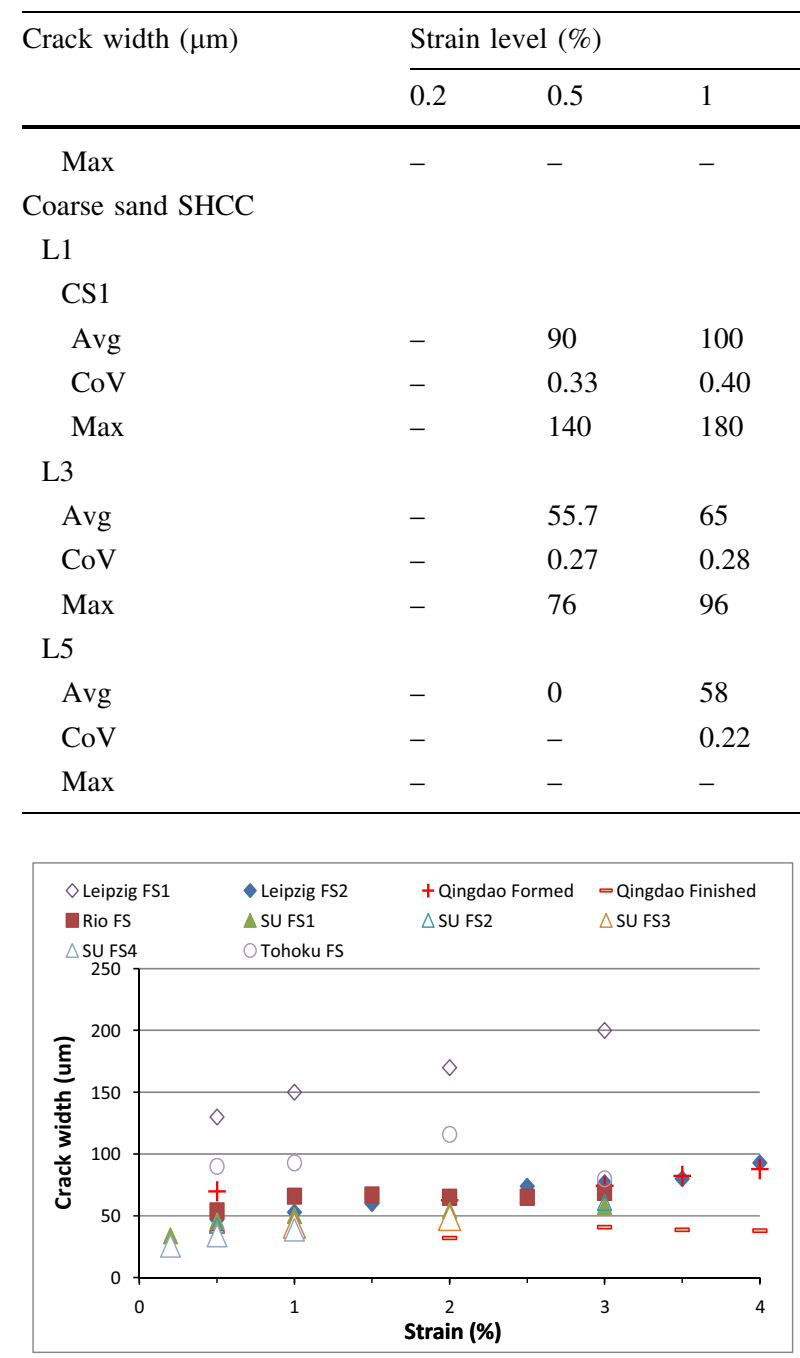

(a)

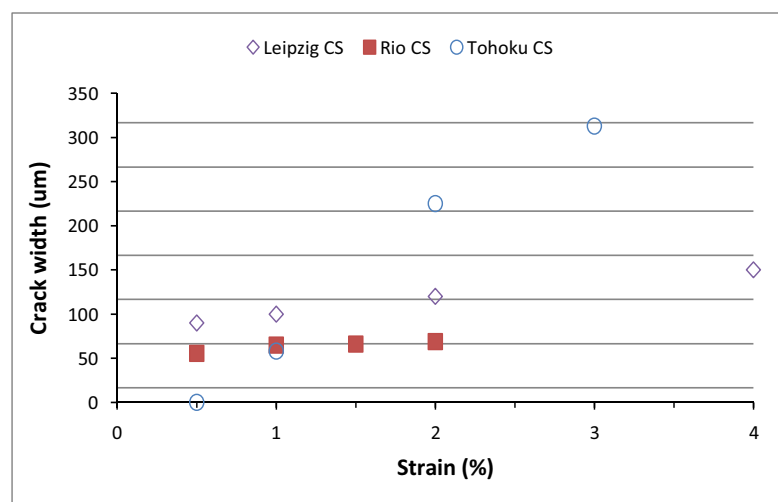

(b)

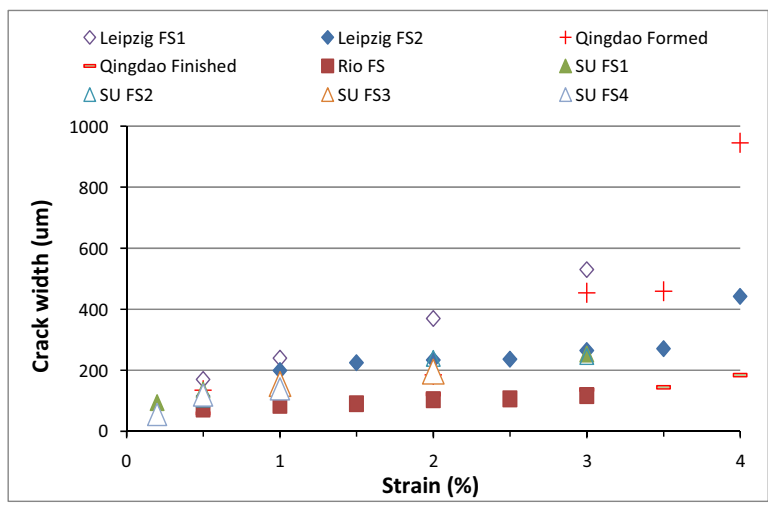

(c)

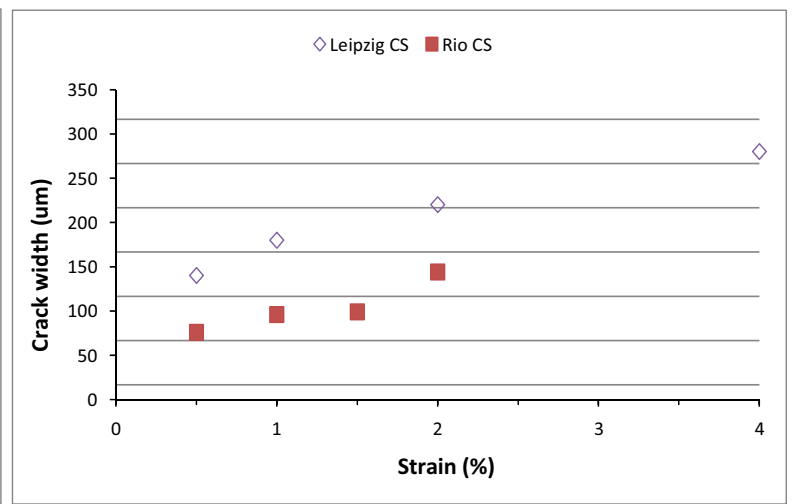

(d)

Fig. 4 Average crack widths for a FS and b CS specimens and maximum crack widths for $\mathbf{c}$ FS and $\mathbf{d}$ CS specimens

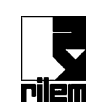




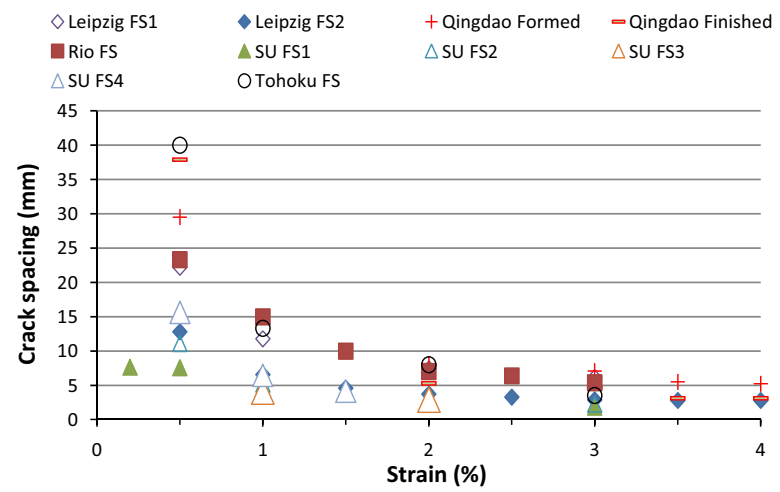

(a)

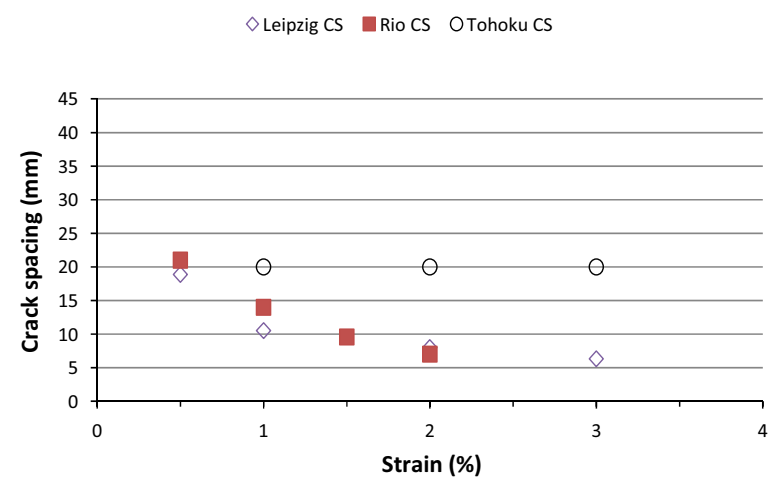

(b)

Fig. 5 Average crack spacing for $\mathbf{a}$ fine sand and $\mathbf{b}$ coarse sand specimens

Table 5 Crack spacing data summary from all participating laboratories

\begin{tabular}{|c|c|c|c|c|c|c|c|c|c|}
\hline \multirow{2}{*}{$\begin{array}{l}\text { Fine sand SHCC } \\
\text { Avg crack spacing (mm) }\end{array}$} & \multicolumn{9}{|c|}{ Strain level $(\%)$} \\
\hline & 0.2 & 0.5 & 1 & 1.5 & 2 & 2.5 & 3 & 3.5 & 4 \\
\hline \multicolumn{10}{|l|}{ L1 } \\
\hline FS1 & - & 22.2 & 11.8 & - & 7.4 & - & 6.1 & - & - \\
\hline $\mathrm{FS} 2$ & - & 12.8 & 6.6 & 4.6 & 3.7 & 3.3 & 2.9 & 2.8 & 2.8 \\
\hline \multicolumn{10}{|l|}{$\mathrm{L} 2$} \\
\hline Formed surface & - & 29.5 & - & - & 8.1 & - & 7.1 & 5.5 & 5.2 \\
\hline Finished surface & - & 37.9 & - & - & 5.3 & - & 4.7 & 3.1 & 3.1 \\
\hline L3 & - & 23.3 & 15 & 10 & 7 & 6.4 & 5.4 & - & - \\
\hline \multicolumn{10}{|l|}{ L4 } \\
\hline FS1 & 7.6 & 7.6 & 4.3 & - & 2.4 & - & 1.8 & - & - \\
\hline FS2 & - & 11.1 & 5.2 & - & 3 & - & 2.2 & - & - \\
\hline FS3 & - & - & 4.1 & - & 2.9 & - & - & - & - \\
\hline FS4 & 16 & 6.5 & 4.1 & - & - & - & - & - & - \\
\hline L5 & - & 40 & 13 & - & 8 & - & 3.5 & - & - \\
\hline \multicolumn{10}{|l|}{ Coarse sand SHCC } \\
\hline \multicolumn{10}{|l|}{ L1 } \\
\hline CS1 & - & 18.9 & 11 & - & 8 & - & 6.3 & - & - \\
\hline L3 & - & 21.0 & 14 & 9.6 & 7 & - & - & - & - \\
\hline L5 & - & - & 20 & - & 20 & - & 20 & - & - \\
\hline
\end{tabular}

As noted in the previous section, large variability in crack width was reported for uniaxial tensile test specimens of small gauge cross sections. Based on the results, a cross section of least dimension of $30-40 \mathrm{~mm}$ is recommended. This thickness recommendation is also in agreement with a typical depth of a SHCC class of applications such as overlay repairs, whereby the actual conditions are simulated appropriately.

Subsequent or simultaneous durability test procedures may also dictate the specimen dimensions. Specimen diameters for permeability tests are addressed here based on the comparative test results. 
Fig. 6 Typical crack width distributions at different strain levels

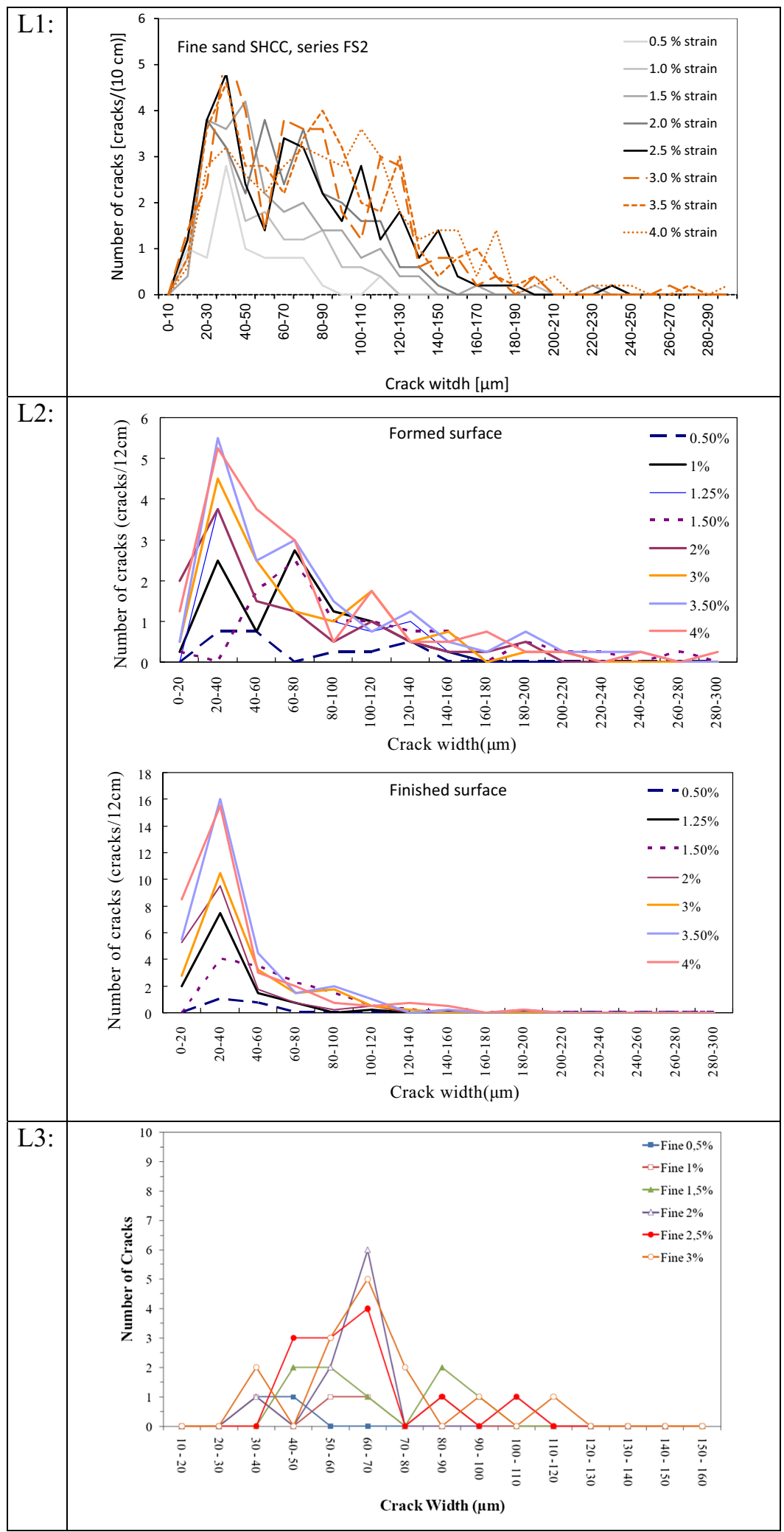


Fig. 6 continued

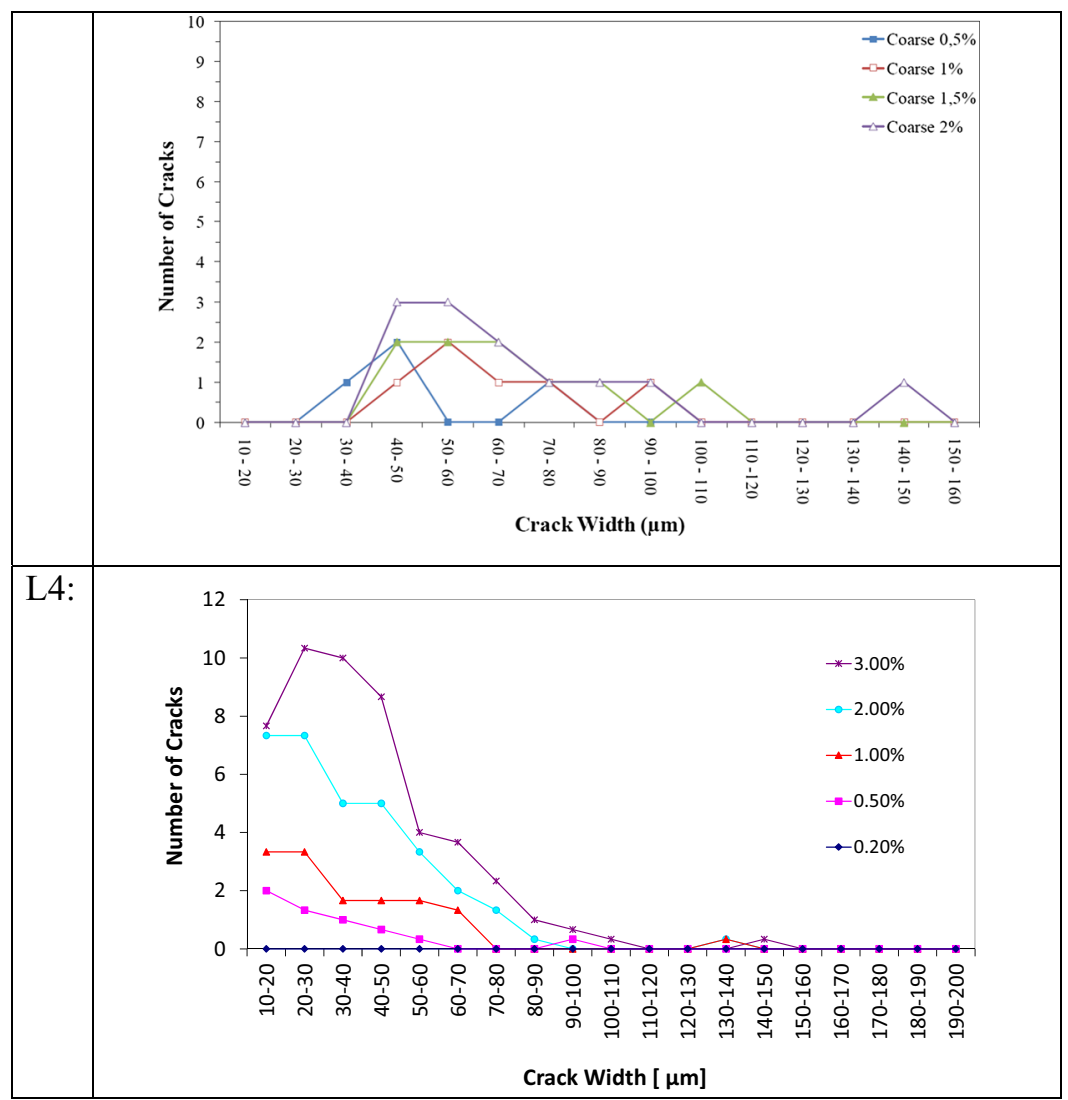

generally in the range of 50-100 mm, while capillary absorption specimens typically have a height of at least $60 \mathrm{~mm}$ (e.g. [17]). To allow such testing, a larger cross-section dimension in the range of $60-100$ is recommended.

The gauge length ranging from 80 to $120 \mathrm{~mm}$ in these comparative tests appeared to have allowed multiple crack formation. In only one set of results, i.e. from L3, a larger cross section $(30 \mathrm{~mm} \times 30 \mathrm{~mm})$ was accompanied by the minimum gauge length of $80 \mathrm{~mm}$. Nevertheless low variability in crack data was found, although cracks predominantly formed in the central part, as seen in Fig. 2 for L3. In the L1 specimens (see Fig. 2), the $120 \mathrm{~mm}$ gauge length allowed a longer central portion to form saturated multiple cracking (zones II and III in Fig. 2). Thus, durability test samples taken from a larger length may be more representative for the durability of actual field SHCC where uniformly spaced cracks may form. A specimen with a longer central part of uniform section may also allow taking two samples from each dumbbell specimen. Thus, a gauge length of $120 \mathrm{~mm}$ is recommended.

From the reported results, it is not possible to distinguish the specimen size and test boundary conditions as sources of variability in crack data. Nevertheless, the data presented for larger specimens had rotationally fixed boundaries at each end, while rotationally semi-free ends were used with the smaller specimens. Carefully applied fixed-fixed boundaries should be preferred in order to activate most of the material's strain capacity, see Sect. 4. However, if it is impossible to accommodate geometrical imperfections in specimens and adapters, a set of rotationally fixed-free boundaries is recommended, i.e. fixed at one end, and free at the other end.

For crack width characterization, either DIP or DIC is recommended, but a resolution of at most $10 \mu \mathrm{m}$ must be used to avoid significant errors. A useful presentation of crack width data is shown in Fig. 6, in the form of crack width histograms. This representation is believed to allow eventual linking of crack distributions with deterioration 
resistance. In addition, average crack widths per set, standard deviation, maximum crack widths as well as average crack spacing must be reported, although all these values might be derived from the histogram data with reasonable accuracy. The durability of cracked SHCC as dependent on the crack pattern is a major subject of investigation for RILEM Technical Committee 240-FDS.

An alternative way of presenting crack width distributions is the so-called crack width polygon [12]. The format of such curves resembles the one of grain size distribution curves and allows to present the crack width distribution independent on crack density or spacing. It is also possible to characterize the crack width distribution by a single numerical value based on the crack width polygon.

It has to be considered that only the average value of the crack spacing can be derived from the observed number of cracks since SHCC crack patterns do not necessarily comprise equally spaced cracks. Determination and evaluation of crack spacing distributions will be subject of further investigations since the crack spacing is expected to have a significant influence on the capillary absorption of cracked SHCC.

\section{Conclusions}

The results of a comparative tensile test series performed by five laboratories have been reported here, with the purpose of identifying a consistent method of pre-cracking SHCC specimens for durability testing. The results indicate various similarities in the data, despite varying local ingredient materials, test procedures, specimen sizes and crack characterisation methods. Keeping in mind that the laboratories were reasonably experienced in performing the tensile tests on SHCC, the results have been interpreted in terms of physical parameters such as specimen geometrical size, test boundary conditions and observation resolution rather than human execution uncertainties. It is acknowledged that this is an assumption.

The following conclusions are drawn:

- Although the average crack width is stabilized in the range of 40-80 $\mu \mathrm{m}$ for a large range in tensile deformation, the maximum crack width may exceed $100 \mu \mathrm{m}$ at a strain of $0.5 \%$, and reach beyond 200 and $250 \mu \mathrm{m}$ at strains of 2 and $3 \%$, respectively.

- Average crack spacing evolves with tensile deformation from $7-40 \mathrm{~mm}$ at $0.5 \%$ average tensile strain to $2-7 \mathrm{~mm}$ at about $3 \%$ strain. Crack spacing appears to stabilize at roughly $3 \%$ average tensile strain for the SHCC tested here.

- SHCC can be prepared from natural sand containing particles of size up to $1-1.2 \mathrm{~mm}$, although a lower ductility and lower ultimate tensile strength than for specimens containing only fine sand with maximum particle size $0.2-0.3 \mathrm{~mm}$ have been found here.

The following recommendations are made:

- The SHCC tensile specimen size of thickness 30-40 mm, width $60-100 \mathrm{~mm}$ and length of the prismatic section of $120 \mathrm{~mm}$ is recommended for pre-cracking or simultaneous durability testing. This recommendation is based on larger scatter of results observed in smaller sections.

- The tensile test setup should comprise of two rotationally fixed ends or, alternatively, of one rotationally fixed end, and one free end.

- Digitally obtained crack width measurements should be obtained with a resolution of at most $10 \mu \mathrm{m}$.

- A crack width distribution histogram is recommended as useful data to link crack distribution and deterioration processes towards durability modelling.

\section{References}

1. Boshoff WP, Adendorff CJ (2013) Effect of sustained tensile loading on SHCC crack widths. Cem Concr Compos 37(2013):119-125

2. Boshoff WP, van Zijl GPAG (2007) Time-dependent response of ECC: characterisation of creep and rate dependence. Cem Concr Res 37(2007):725-734

3. Kwon S, Nishiwaki T, Kikuta T, Mihashi H (2014) Development of ultra-high-performance hybrid fiber-reinforced cement-based composites. ACI Mater J 111:309-319

4. Mechtcherine V (2007) Testing behaviour of strain hardening cement-based composites in tension - summary of recent research. In: RILEM-Symposium on high-performance fibre reinforced cementitious composites, RILEM PRO 53, pp 13-22

5. Mechtcherine V (2011) Tensile tests, Chapter 3. In: Fischer $\mathrm{G}$ (ed) Mechanical characterisation and testing of strain hardening fibre-reinforced cement-based composites. State 
of the art report prepared by Subcommittee 1 of RILEM Technical Committee 208-HFC

6. Mechtcherine V, Lieboldt M (2011) Permeation of water and gases through textile reinforced concrete. Cem Concr Compos 33(7):723-734

7. Magalhães MS, Toledo Filho RD, Fairbairn EMR (2014) Influence of local raw materials on the mechanical behaviour and fracture process of PVA-SHCC. Mater Res 17(2014):146-156

8. Paul SC, van Zijl GPAG (2013) Mechanically induced cracking behaviour in fine and coarse sand strain hardening cement based composites (SHCC) at different load levels. J Adv Concr Technol 11:301-311

9. Van Zijl GPAG, Wittmann FH, Oh BH, Kabele P, Filho RD, Fairbairn EMR, Slowik V, Ogawa A, Hoshiro H, Mechtcherine V, Altmann F, Lepech MD (2012) Durability of strain-hardening cement-based composites (SHCC). Mater Struct 45(10):1447-1463

10. Van Zijl GPAG, Wittmann FH (2010) On durability of SHCC. J Adv Concr Technol 8:261-271

11. Van Zijl GPAG, Wittmann FH (eds) (2011) Durability of strain-hardening fibre-reinforced cement-based composites (SHCC). State-of-the-art report, Rilem TC 208 HFC, SC 2, Springer Publishers, ISBN-13: 978-94-007-0337-7

12. Wagner C, Dolase A, Slowik V (2012) Evaluation of crack patterns in SHCC with respect to water permeability and capillary suction. In: Alexander MG (ed) Proceedings of the 3rd international conference on concrete repair, rehabilitation and retrofitting (ICCRRR 2012), September 3-5, 2012, Cape Town, South Africa. CRC Press, Leiden, pp 972-977

13. Wagner C, Slowik V (2011) Strain hardening cement-based composites for repair layers on cracked concrete surfaces. In: Grantham M, Mechtcherine V, Schneck U (eds) Proceedings of concrete solutions, 4 th international conference on concrete repair, September 26-28, 2011, Dresden, Germany. Taylor \& Francis Group, London, pp 775-782

14. Wagner C, Slowik V, Waldenburger K (2008) Dehnungsverfestigendes zementgebundenes Material für die Sanierung gerissener Betonflächen (Strain hardening cement-based material for the repair of cracked concrete surfaces). Bautechnik 85(1):49-56

15. Wang P, Wittmann FH, Zhao, T, Huang W (2011) Evolution of crack patterns on SHCC as function of imposed strain. In: Proceedings 2nd int. RILEM conf. on strain hardening cementitious composites, September 12-14. Rio de Janeiro, Brazil, pp 217-224

16. Wille K, El-Tawil S, Naaman AE (2014) Properties of strain hardening ultra high performance fiber reinforced concrete (UHP-FRC) under direct tensile loading. Cem Concr Compos 48(2014):53-66

17. Zhang P, Wittmann FH, Zhao TJ, Lehmann EH, Tian Vontobel P (2010) Observation and quantification of water penetration into strain-hardening cement-based composites (SHCC) with multiple cracks by means of neutron radiography. Nucl Instrum Methods Phys Res A 620(2010a):414-420 